\title{
WERNER ZIEGENFUSS
}

\section{LENIN \\ SOZIOLOGIE UND REVOLUTIONARE AKTION IM POLITISCHEN GESCHEHEN}

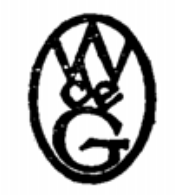

BERLIN 1948

WALTER DE GRUYTER \& CO.

vormals G. J. Goschen'sche Verlagshandlung - J. Guttentag Verlags.

buchhandlung - Georg Relmer - Karl J. Trübner - Veit \& Comp. 


\section{LEBENDIGE SOZIOLOGIE}

Schriften und Texte zum Studium der modernen Gesellschaft und der Gesellschaftslehre

Herausgegeben von

Werner ZiegenfuB

Archiv-Nr. 424748

Druckgenehmigungsnummer 9952 der Nachrichten-Kontrolle der Amerikanischen Militär-Regierung

Druck: Achilles \& Schwulera, Berlin SW 61, Reg.-Nr. 22 32. - 2200. 5. 48. 
"Es gibt keine abstrakte Wahrheit, die Wahrheit ist immer konkret "

(Lenin, ,Zwei Taktiken in der sozialdemokratischen Revolution", Kap. X) 
